\title{
EVOLUTION OF TV STANDARDS
}

\section{Chair: CRISTIANO AKAMINE - Researcher and Professor - UNIVERSIDADE MACKENZIE/ SET}

Digital TV is a reality in the world and, here in Brazil, analogue TV will be shut down in the largest centers by the end of 2017. But does that evolution stop there? In this panel, we will hear about the next generations of open TV being developed around the world.

- R\&D FOR NEXT GENERATION TERRESTRIAL BROADCASTING IN JAPAN

Speaker: Kenichi MURAYAMA Senior Research Engineer Advanced Transmission Systems Research Division Science \& Technology Research Laboratories NHK

Last August, the trial broadcasting of Super Hi-Vision by satellite in Japan had been lauched with our predetermined schedule. Moreover, studies to realize next-generation terrestrial broadcasting are planned. NHK STRL has been conducting R\&D on large-capacity transmission technologies to realize terrestrial Super Hi-Vision broadcasting and TV-Globo and NHK had successfully conducted 8K terrestrial transmission experiments during Rio Olympics. This presentation mainly introduces an overview of R\&D for next generation terrestrial broadcasting in Japan.

- NEXT-GEN TV - THE ATSC 3.0 STANDARD Speaker: Skip Pizzi - Vice President, Technology Education and Outreach (NAB)

The world's most advanced terrestrial broadcast television standard is nearing completion, and early deployments are already underway. This presentation will provide an overview of the system's unique characteristics and advantages for broadcasters and their audiences.

- INNOVATIVE APPLICATIONS FOR NEXT GENERATION BROADCASTING 


\section{Speaker: Lisa Hobbs - Commercial Portfolio Strategy - Compression Solution Area Media - Ericsson}

Terrestrial television broadcasting has changed very little since the first over the air broadcasts were conducted. Technology has changed: black and white to color, analog to digital, improved compression algorithms. But generally the application has remained free to air television transmission to the masses. All that is about to change, however, with the realization of the new ATSC 3.0 standard. At its core, the standard still provides a means to transmit programming over the air to consumers. But if broadcasters think this is simply a new way to do what they've always done-they are unlikely to be broadcasters in the long term. ATSC 3.0 consists of standards designed to allow broadcasters to achieve the goal of "anytime, anywhere" content already embraced by content providers and cable/satellite/telco operators. It allows them to deliver different content based on viewer preferences. And it allows them to achieve all this by leveraging some of the technologies currently utilized by mobile operators-bringing the possibility of future cooperation into the realm of possibility. This presentation will focus on some of the new applications expected to be launched by broadcasters leveraging the ATSC 3.0 standard, and the application already commercially launched in Korea. The hope is to start broadcasters elsewhere in the world thinking about new ways to leverage their own existing (or perhaps newly modified) standards in order to realize similar opportunities in their own markets

- NEW GENERATION OF SOFTWARE BASED ENCODING: BARE METAL, DOCKER AND NEW FEATURES TO SUPPORT 4K/8K. Speaker: Sidnei Brito - Sales Director - SDB MULTIMIDIA - Harmonic Authorized

He presentation will discuss new trends and technologies to handle the amount of data and new enhancements that come with $4 \mathrm{~K} / 8 \mathrm{~K}$ formats.

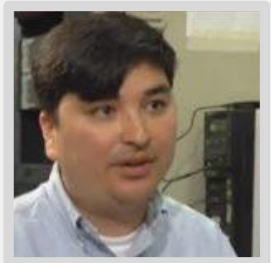

\section{CRISTIANO AKAMINE - Researcher and Professor - UNIVERSIDADE MACKENZIE/ SET}

He holds a degree in Electrical Engineering from Mackenzie Presbyterian University (1999), a master's degree and a Ph.D. in Electrical Engineering from the State University of Campinas (2004/2011). He is a researcher at Mackenzie's Digital TV Research Laboratory since 1998. He took an internship at NHK Laboratories for Research in Science and Technology (STRL) and was Visiting Specialist Professor at Unicamp's Faculty of Technology. Currently, he is a professor in Electrical Engineering and the Post-Graduate Program in Electrical and Computer Engineering (PPGEEC) of Mackenzie Presbyterian University and Coordinator of Mackenzie's Digital TV Research Laboratory. He has a scientific grant of Productivity and Technological Development and Innovative Extension - Level 2 from National Counsel of Technological and Scientific Development (CNPq). He is also a member of the Board of the Brazilian Digital Terrestrial Television (SBTVD) Forum. He has several patents and 

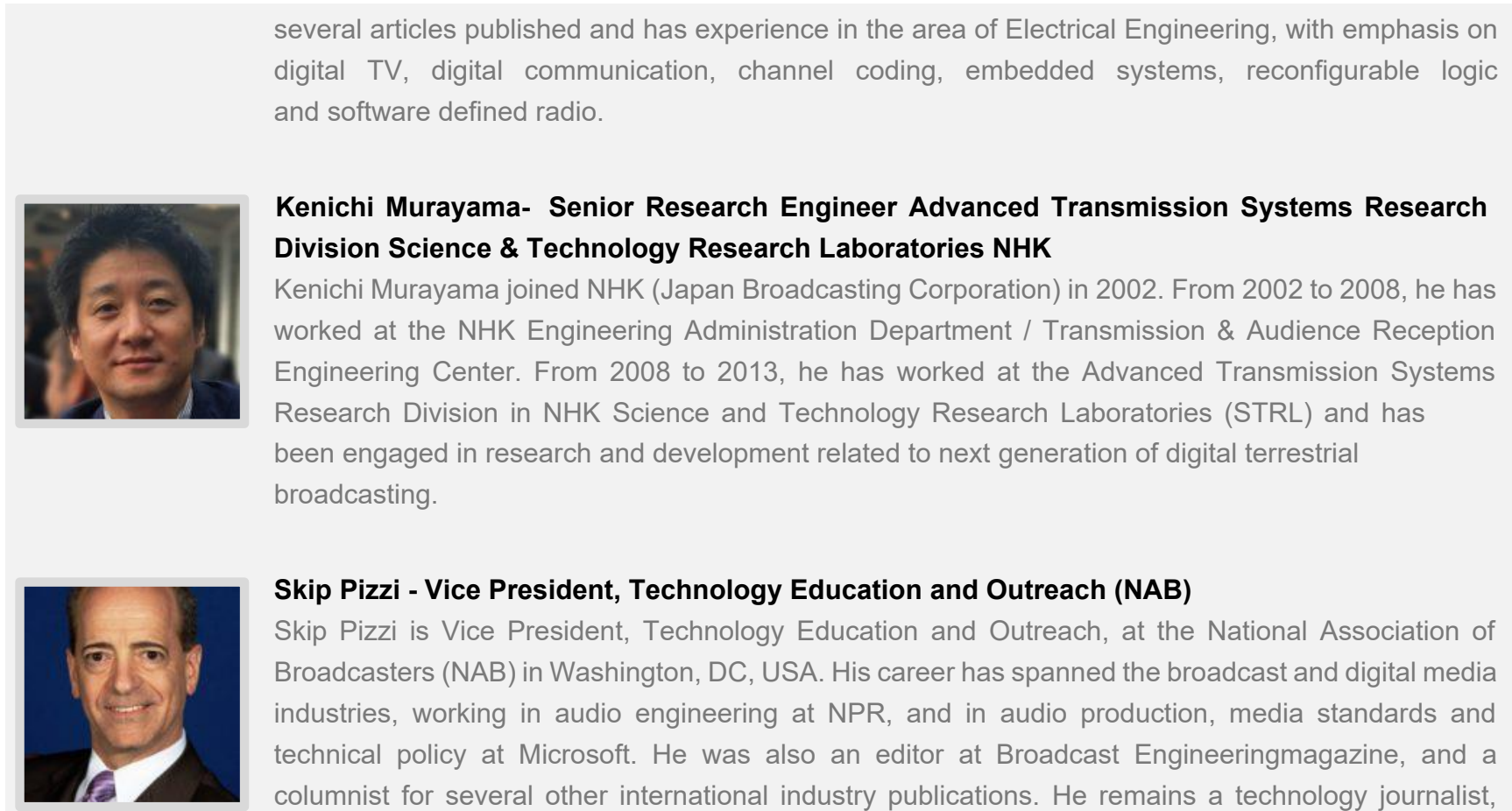

\section{Skip Pizzi - Vice President, Technology Education and Outreach (NAB)}

Skip Pizzi is Vice President, Technology Education and Outreach, at the National Association of Broadcasters (NAB) in Washington, DC, USA. His career has spanned the broadcast and digital media industries, working in audio engineering at NPR, and in audio production, media standards and technical policy at Microsoft. He was also an editor at Broadcast Engineeringmagazine, and a columnist for several other international industry publications. He remains a technology journalist, editor, author and trainer today. His most recent book is A Broadcast Engineering Tutorial for NonEngineers, 4th edition, published by Focal Press. He is currently Associate Editor on the NAB Engineering Handbook, 11th edition, which will be published later this year. Skip serves as ViceChair of the Advanced Television Standards Committee (ATSC) Technology Group 3 (TG3), which is developing the ATSC 3.0 standard. He is also a member of the Board of Directors of the Ultra HD Forum. Skip is a graduate of Georgetown University, where he studied Electrical Engineering, International Economics and Fine Arts.

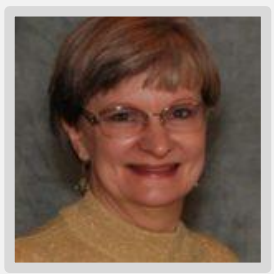

\section{Lisa Hobbs - Commercial Portfolio Strategy - Compression Solution Area Media - Ericsson}

Lisa Hobbs joined Ericsson in 1997 after spending nine years in the satellite communications and video compression divisions of Scientific-Atlanta (now Cisco.) As Vice President, Compression Commercial Portfolio Strategy for Ericsson, she shares global responsibility for defining the direction of the compression portfolio across all of the market segments in which Ericsson has a presence, with a focus on market direction and ROI.

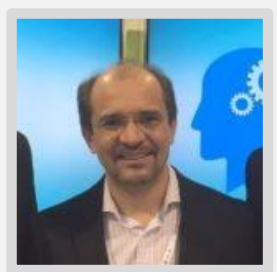

\section{Sidnei Brito - Sales Director - SDB MULTIMIDIA - Harmonic Authorized}

Electronic Engineer graduated from Pontificia Universidade Católica, with more than 20 years of experience in the television area. He is currently Commercial Director of SDB Multimidia, Platinum Partner and Harmonic Authorized Repair Center in Brazil. 